\title{
A Framework for Enhancing Competitive Intelligence Capabilities using Decision Support System based on Web Mining Techniques
}

\author{
I. Anica-Popa, G. Cucui
}

Ionuţ Anica-Popa Academy of Economic Studies of Bucharest, Romania

E-mail: ionut.anica@ase.ro

Gabriel Cucui Valahia University of Targoviste, Romania

\begin{abstract}
Nowadays Competitive Intelligence (CI) represents one of the most important pieces in strategic management of organizations in order to sustain and enhance competitive advantage over competitors. There are some studies that claim that a successful strategic management is influenced by the accuracy of external environment's evaluation and, in the same time, in order to have correct and complete business strategies it is necessary to be sustained by competitive advantage. But till at the beginning of ' 80 the things were totally different. This paper will present the evolution and the objectives of CI, the results of using CI in organizations and how can be improved the CI process using tools and techniques provided by business intelligence (BI). The study will propose a framework of a decision support system based on web mining techniques in order to enhance capabilities of organization's competitive intelligence.
\end{abstract}

Keywords: competitive intelligence, information system, decision making process, web mining

\section{Introduction}

Several studies ([13], [27], [30], [28], [32]) consider that starting with the second half of the 20th century a series of researches were focused on the enhancing competitiveness of the organization based on concept of intelligence as a process. [3], [37] state that the accuracy of external environment's evaluation has a big influence over a successful strategic management and correct and complete business strategies must be sustained by competitive advantage. In the context of using methods and tools provided by information technology and communication (ITC), the increasing significance of using information and knowledge in order to obtain a competitive advantage and the enhancing ability of organization in order to maximize the efficiency of using internal and external linkages through new data and information flows [32] represent an activity which must be closely supervised in every organization.

There are studies claiming that competitive intelligence (CI), as a research area, attracted growing attention over the last two decades and especially in the last years ([7], [5]). Some of the main factors which had a great influence over this evolution are: (1) spectacular development of the information technology and communication (ITC) domain, (2) methods and tools provided by ITC, (3) exponentially use of the Internet, many CI researchers considering that Internet represents the one of the major information data sources used by CI ([36], [41], [5]).

The research objectives of this study are outlined below:

- presenting a short overview of competitive intelligence (CI) evolution and possible ways of developing in future; " identifying the objectives of using competitive intelligence (CI) in organizations;

- presenting a short overview of some specific tools and techniques provided by business intelligence (BI) which can be used in competitive intelligence;

- identifying the results of using competitive intelligence (CI) in organizations; 
- proposing a framework for a decision support system using web mining techniques.

An extensive review of literature will be conducted in order to accomplish the goals of this study.

\section{Definition and evolution of competitive intelligence}

The literature related to intelligence suggests that are three directions for this area [5]:

- the first is represented by the military domain where can be identified one of the earliest studies regarding intelligence, which is The Art of War by Sun Tzu (translated by Griffith in 1963);

- the second is represented by the national security as a policy issue [4];

- the third is represented by the economic domain, where the intelligence determines an increasing competitiveness of organizations [12].

[21] consider that information is factual because consist in numbers, indicators, data about competitors, customers, suppliers regarding past actions of them, but intelligence represents a collection of cleaned, filtered and analyzed information that support managers in decision making process.

The modern approach of competitive intelligence (CI) was appeared after the second world war and started to become important in the ' 80 [15], the indicators that are sustaining this being:

- the number of conferences having the topic competitive intelligence (CI) which is increasing constantly;

- the increasing number of books, articles, studies, papers and other types of publication about competitive intelligence $(\mathrm{CI})$;

- the increasing number of academic courses and professional programs dedicated to competitive intelligence $(\mathrm{CI})$;

- the developing and increasing role of Society of Competitive Intelligence Professionals (SCIP) which is a global organization with declared mission to "be the global organization of choice for professionals engaged in competitive intelligence and related disciplines" and to "be the premier advocate for the skilled use of intelligence to enhance business decision-making and organizational performance" (www.scip.org) and having the declared vision: "Better decisions through competitive intelligence".

Starting with the 1980 an important number of researchers tried to define the concept of competitive intelligence (CI).

$\mathrm{CI}$ it is represented by information which describe how competitive is an organization and, in the same time, it is being able to predict moves of the business environment actors (competitors, customers, suppliers, government etc) [16].

CI represents an iterative and systematic process for gathering and analyzing data and information about activities of competitors, business environment and business trends in order to fulfill the goals of organization [21].

CI represents a process that predicts behavior and moves of the actors (competitor, customer, suppliers, government etc) which interact with organization or influence either the business environment or the behavior of organization [6]. The results provided by CI are used in order to identify potential business opportunities and to minimize the possibility of appearance for unpredictable situations, those facts define the goal of the CI: to predict the future situations (what is going to happen) rather than debate past situations (what did happen). 
$\mathrm{CI}$ is a process that aims to monitor the external business environment of organization in order to identify relevant information for decision making process [9].

Competitive intelligence represents a process that consists of two levels [25]:

- Accessing legal and ethical data sources (publicly or semipublicly) in order to gather data for building new data sources regarding competitors, competition, environmental conditions, past, present or future trends etc.

- Analyzing those new data sources in order to transform data into usable and valuable information and knowledge that will support the decision making process.

Summarizing all those points of view we consider that competitive intelligence represents a continuous process of gathering data, information and knowledge about actors (competitors, customers, suppliers, government etc) which interact with organization in the business environment in order to support decision making process for enhancing competitiveness of organization.

The CI process consists in the following steps: monitoring business environment (external data, information and knowledge), gathering, analyzing, filtering and disseminating intelligence that will support decision making process in order to increase competitiveness and improve position of organization.

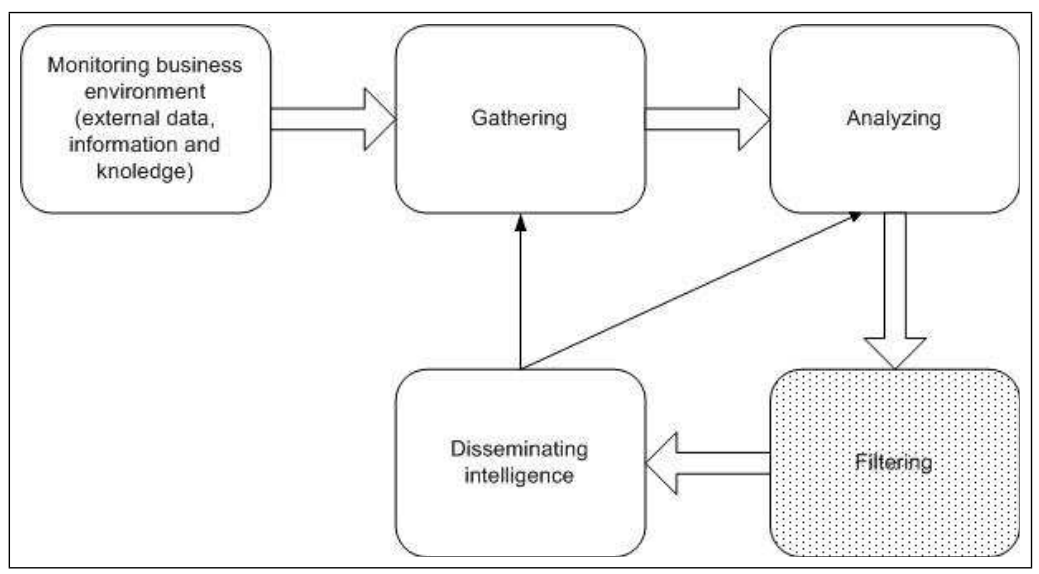

Figure 1: Competitive Intelligence $(\mathrm{CI})$ process

[33] considers that evolution of CI could be divided in following stages: (1) "Competitive Intelligence Gathering" occurred through the 60s and 70s; (2) "Industry and Competitor Analysis" occurred through 1980 and 1987; (3) "Competitive Intelligence for Strategic Decision Making" occurred through 1987 and 2000; (4) "Competitive Intelligence as a Core Capability" which represent the present stage in CI evolution.

In the Competitive Intelligence Gathering stage of CI the key defining event was the book "Competitive strategy" published by Michael Porter in 1980. Personnel involved in CI activities were located mostly in Library or Marketing department and the primary skill was capability to find information [33]. Despite the fact that organization was collected large amount of data, over gathered data rarely were applied some static analyses. Another important thing was represented by very weak connection between $\mathrm{CI}$ and decision making process. Development of skills in information acquisition was the key issue of this stage.

In the Industry and Competitor Analysis stage of CI the key defining event was the founding of the Society of Competitive Intelligence Professionals (SCIP). Personnel involved in CI activities were located mostly in Planning or Marketing department, over gathered data were applied quantitative analyses, and between $\mathrm{CI}$ and decision making process was a weak connection [33]. Building a business case for CI, spy image and analytical skill development were the keys issues of this stage. 
In the Competitive Intelligence for Strategic Decision Making stage of CI the key defining event was the establishment of the Competitive Intelligence Review. Personnel involved in CI activities were located mostly in Planning, Marketing or CI unit, over gathered data were applied quantitative and qualitative analyses, and between $\mathrm{CI}$ and decision making process was a strong connection. Demonstrating bottom-line input, role of information technology, CI technology, international CI, demands vs. supplydriven CI, counter-intelligence were the keys issues of this stage [33].

In the Competitive Intelligence as a Core Capability stage of CI the key defining event is represented by $\mathrm{CI}$ courses taught in universities and in business school across the world. Personnel involved in CI activities are located mostly in CI units, Planning or Marketing, over gathered data are be applied qualitative emphasis analyses and information and knowledge provided by $\mathrm{CI}$ represent a raw material for decision making. Managing the parallel process, intelligence infrastructures for multinationals, $\mathrm{CI}$ as learning, network analysis are the keys issues of this stage.

\section{The objectives and results of using CI in organizations}

From the beginning is important to emphasize that is not necessary that every organization to develop and implement an organized CI activity. In many cases formal information gathered from external sources (Internet, media, government etc) and informal data and information collected, analyzed and filtered by managers represent a very flexible and efficient informal CI. But in the case of some organization, an informal CI is not enough in order to support tactic and strategic decision making process, fact that conduct to develop and implement an organized CI system. The CI can be used in order to increase the capabilities of the organizational memory $(\mathrm{OM})$ of the enterprise because the OM contains organizational memory information systems which are based on Knowledge Management techniques [39].

In the last years, enterprises are constantly working to improve and to enhance their operations [40]. The reasons which are staying at the base of decision to implement a CI in organization are various [21]:

- The globalization process which determine an increasing level of competition among organizations because the number of competitor is increasing and, in the same time, the quantity and quality of goods and services provided by them growing continuously.

- The new products, services, methods and tools provided by information technology and communication domain.

- The rapidly changing of the business environment where new business opportunities appear and disappear very fast and the period of time allocated for decision making processes is decreasing constantly.

- Political changes which affect and influence the business environment as well as the evolution of organizations.

A review of the literature related to objectives of using CI in organization reveals quite a wide and ambitious arrangement of objectives for CI [31].

[1] consider that objectives of using an organized information system of CI are: (1) identifying and analyzing new business opportunities or the market trends; (2) developing or updating software using latest technologies, methods and tools for software developing; (3) maximizing revenues and minimizing expenses; (4) identifying, understanding and analyzing strategies, already implemented or in the phase of implementation.

[31] consider that objectives of using an organized information system of CI are: (1) help organization in order to gain a competitive edge; (2) reveal opportunities and threats by surveying weak signals; 
(3) process and combine data, information and knowledge in order to produce new knowledge about competitors, customers, suppliers etc.; (4) provide useful information for managers in decision making process and reduce the period of time used by decision making process.

In our opinion, the objectives of using an organized information system of $\mathrm{CI}$ in organizations are:

- Enhancing organization's competitiveness.

- Predicting, with a high level of trust, business environment's evolutions, competitors' actions, customers' requirements, even influences generated by political changes.

- Providing a better and better support for strategic decision making process.

There are studies that identify some benefit derived from using organized information system of CI [16]: (1) increasing analytical skill for managers and the ability to anticipate moves of the other actors from organization's business environment; (2) sharing ideas and knowledge inside organization in order to develop new ideas or knowledge or to integrate the existing into organization.

Some authors identified new benefits from using organized information system of CI [21]: (1) discovering new potential competitors or customers and supporting starting of new businesses (2) identifying and analyzing new technologies, products and processes that influence organization's activities and behavior; (3) identifying and analyzing political or legislative standards or regulations that influence organization's activities and behavior; (4) identifying and analyzing situations, from competitors, customers, suppliers or other, that evolved into successes or into failures.

\section{Decision Support System and Web Mining}

In the last years, due to the economic evolution, the amount of data and information which must be used in order to adopt better decision has increase extraordinary; therefore the decisional process from organizations has a spectacular evolution [42]. Companies gathering data from a various sources and deposit them in data warehouses which represent a collection of subject-oriented, integrated, timevariant and non-volatile data used in order to support the process of decision-making [20]. Each person involved in the process of decision-making can and must be supported in performing his activities by specialized IT tools [14]. [8] consider that Decision Support Systems (DSS) represents a specific class of information system that supports business and organizational decision-making activities.

[19] state that business intelligence represents the ability of companies of analyzing and studying the behavior and actions from previous periods of time in order to understand actual position of organization and to predict or try to change what is going to happen in future period of time. [35] consider that business intelligence is composed from following components: (1) Extraction, Transformation and Loading ETL; (2) Data mining; (3) Online Analytical Processing - OLAP; (4) Enterprise reporting.

In last decade, the Internet growing was spectacular and the amount of information which reside on the Internet is huge and nowadays the World Wide Web became represents one of the major source of data and information for all activities [11]. In order to extract relevant information from the Web it is necessary to examine and to analyze the content, structure and usage of web resources using techniques of data mining [26]. Because the scope of data mining is the identify patterns which are hidden in large databases [29], in the last decade, the web mining technologies developed in this period determine an increasing of volume of valuable material which can easily browsed and identified over the Internet [18]. Web data mining represents a group of three concepts (Figure 2): web content mining, web structure mining and web usage mining and it is very important to make a clear distinction between these concepts ([10], [24], [22]). [34] consider that web content mining represents "the process of searching for contextually relevant sources of web data whose embedded information can be extracted and used to generate actionable knowledge". [24] consider that "web structure mining tries to discover the model underlying 
the Web hyperlink structure". [34] consider that the web usage mining represents "the process of searching for user behavior patterns by mining the data stored in referrer logs, server access logs, and other web user behavior data repositories".

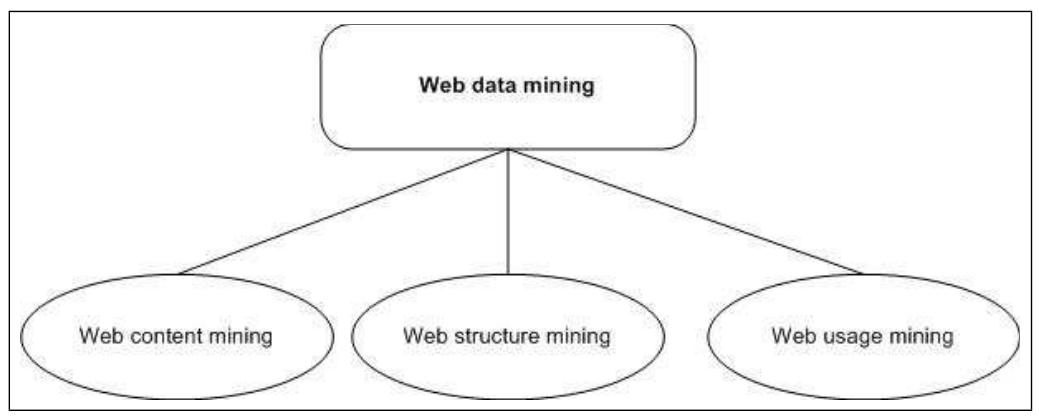

Figure 2: Structure of web data mining

There are studies ([23]; [38]) that consider that web content mining and web structure mining can be used to gather data about business competitors in order to enhance business decision-making and organizational performance

\section{Proposed framework for a Decision Support System using Web mining capabilities}

Because a modern company's information system must also contain data and information acquired from the web which are extremely dynamically. In the same time, during the decision making process, the information system must be updated with the latest data, information and knowledge. In this section will be presented a framework for decision support system using web mining techniques based on architecture consist of three tiers (Figure 3): decision tier, logic tier and data tier.

The decision tier, which is the top-most level of the model, receives the request from the user and invokes the logic tier for resolving the request after translating the request. After the receiving of results from logic layer, the decision layer transposes these into a format that help user to understand and use them.

The logic tier, which is the middle level of the model, has the following functions:

- gather data, information and knowledge from company's information system, invoking data mining algorithms, performing calculation, making evaluations and finally transformation of the obtained data into useful information [2];

- gather data, information and knowledge from the web using specific web mining techniques and provide them to the data tier.

Data tier store and retrieve information from all databases contained by company's information system and transmit then to the logic tier for processing.

\section{Conclusions}

Understanding business environment dynamics and predicting its evolution is a challenging and difficult task for every information system of CI, but represents, in the same time, one of the most expected needs and requirements from organizations. An information system of CI used in an efficient way will determine an increasing level of efficiency of adopted and applied decisions. Information system of CI 


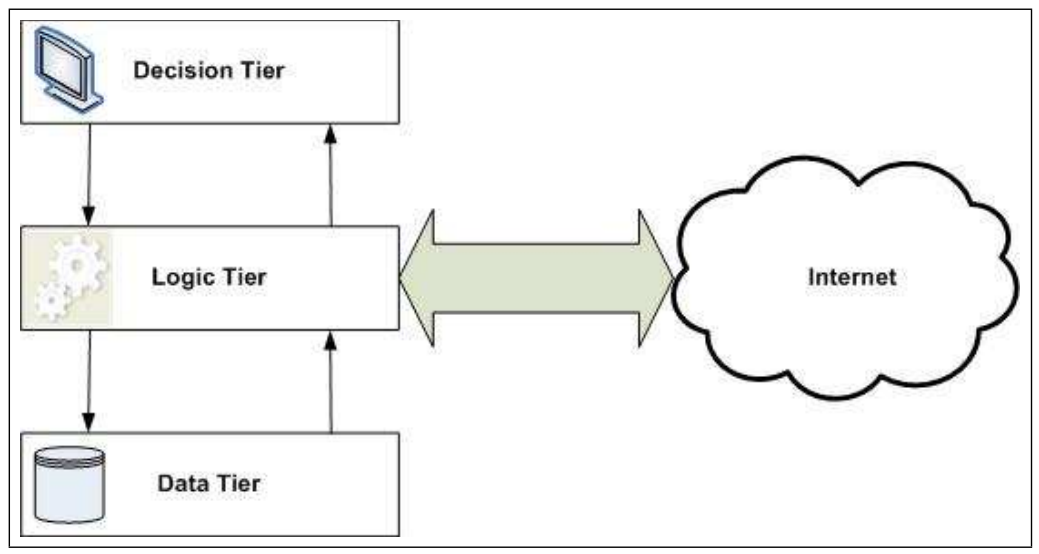

Figure 3: Framework for DSS based on web mining techniques

is recommended to be developed, implemented and used in order to create a competitive advantage over competitors and became more and more evident that CI process is necessary in every organization which intends to increase the existing level of intelligence.

\section{Bibliography}

[1] S. Alampalli, Role of CI in Opportunity Assessment - online version. 2002, Available from: http://www.scip.org/Publications/CIMArticleDetail.cfm?ItemNumber=985 (Downloaded: 21 September 2006).

[2] L. Anica-Popa, I. Anica-Popa, Decision Support in Global Organization, Accounting and Management Information System Journal, Supplement 2006, pp. 536-54, 2006.

[3] T.S. Bateman, S.A. Snell, Management: competing in the new era - 5th ed, New York, NY, McGrawHill Higher Education, 2002.

[4] B.D. Berkowitz, A.E. Goodman, Strategic intelligence for American National Security. Princeton, NJ, Princeton University Press, 1989.

[5] F. Bouthillier, T. Jin, , Competitive Intelligence and Webometrics, Journal of Competitive Intelligence and Management, Volume 3, No. 3, pp. 19-39, 2005.

[6] J. Calof, Increasing Your CIQ - The Competitive Intelligence Edge. EcDevJournal - online version, 1998. Available from: http://www.ecdevjournal.com (Downloaded: 24 June 2006).

[7] C. Carr, G.S. Erickson, H.N. Rothberg, Intellectual capital, competitive intelligence and the Economic Espionage Act, International Journal of Learning and Intellectual Capital, Volume 1, pp. 152-164, 2004.

[8] M. Castellano, G. Mastronardi, A. Aprile, M. Minardi, P. Catalano, V. Dicensi, G. Tarricone, A Decision Support System base line Flexible Architecture to Intrusion Detection, Journal of Software, Volume 2, No. 6, pp. 30-41, 2007

[9] H. Chen, M. Chau, D. Zeng, CI Spider: a tool for competitive intelligence on the Web, Decision Support Systems, Volume 34, pp. 1-17, 2002. 
[10] R. Cooley, B. Mobasher, J. Srivastava, Web Mining: Information and Pattern Discovery on the World Wide Web, in Proceedings of the 9th IEEE International Conference on Tools with Artificial Intelligence (ICTAI'97), Newport Beach, CA, 1997.

[11] I. Dzitac, I. Moisil, Advanced AI Techniques for Web Mining, Proc. of 10th WSEAS International Conference on Mathematical Methods, Computational Techniques and Intelligent Systems, Corfu, Greece, pp. 343-346, 2008.

[12] R. Ecells, P. Nehemkis, Corporate Intelligence and Espionage: A Blueprint for Executive Decision Making. New York, NY, Macmillan, 1984.

[13] W.R. Fair, The corporate CIA - a prediction of things to come, Management Science, Volume 12, No. 10, pp.B489-B503, 1966.

[14] F.G. Filip, Decision support and control for large-scale complex systems, Annual Reviews in Control, Volume 32, No. 1, pp. 61-70, 2008.

[15] C.S. Fleisher, An introduction to the management and practice of competitive intelligence, in C.S. Fleisher, D.L. Blenkhorn (eds.), Managing Frontiers of Competitive Intelligence, Westport, CT, Quorum Books, pp. 3-18, 2001.

[16] B. Gilad, The Role of Organized Competitive Intelligence in Corporate Strategy. Columbia Journal Of World Business, Volume 24, No. 4, pp. 29-36, 1989.

[17] S.E. Griffith, Sun Tzu: The Art of War, New York, Oxford University Press, 1963.

[18] L. Hâncu, Data-Mining Techniques for Supporting Merging Decisions, International Journal of Computers, Communications \& Control, Vol. III, Suppl. issue: Proceedings of ICCCC 2008, pp. 322-326, 2008.

[19] C. Imhoff, M. Galemmo, J.G. Geiger Mastering Data Warehouse Design - Relational and Dimensional Techniques, Indianapolis, IN, Wiley Publishing, 2003.

[20] W. Inmon, Building the Data Warehouse. Fourth Edition, Indianapolis, IN, Wiley Publishing, 2005.

[21] L. Kahaner, Competitive Intelligence: From Black Ops to Boardrooms - How Businesses Gather, Analyze, and Use Information to Succeed in the Global Marketplace, New York, NY, 1996.

[22] J.S. Kim, Customized Recommendation Mechanism Based on Web Data Mining and Case-Based Reasoning, Intelligent Agents for Data Mining and Information Retrieval, Hershey, PA, Idea Group Publishing, 2004.

[23] B. Liu, Y. Ma, P.S. Yu, Discovering Unexpected Information from Your Competitors' Web Sites, Proceedings of the Seventh ACM SIGKDD International Conference on Knowledge Discovery and Data Mining, San Francisco, USA, 2001.

[24] S. Madria, S.S. Bhowmick, W.K. Ng, E.P. Lim, Research Issues in Web Data Mining, Proceedings of Data Warehousing and Knowledge Discovery, First International Conference, Florence, Italy, 1999

[25] J.J. McGonagle, C.M. Vella, A Case for Competitive Intelligence, The Information Management Journal, July/August Edition, Vol. 36 No.4, pp.35-40, 2002.

[26] B. Mobasher, Web Mining Overview, Encyclopedia of Data Warehousing and Mining, Heshey, PA, IdeaGroup, 2006. 
[27] D.B. Montgomery, G.L. Urban, Marketing decision-information systems: An emerging view, Journal of Marketing Research, Volume 7, pp. 226-234, 1970.

[28] D.B. Montgomery, C.B. Weinberg, Toward strategic intelligence systems, Journal of Marketing, Volume 43, pp. 41-52, 1979.

[29] M. Pater, D.E. Popescu, Multi-Level Database Mining Using AFOPT Data Structure and Adaptive Support Constrains, International Journal of Computers, Communications \& Control, Vol. III, Suppl. issue: Proceedings of ICCCC 2008, pp. 437-441, 2008.

[30] F.T. Pearce, Business intelligence systems: The need, development and integration, Industrial Marketing Management, Volume 5, pp. 115-138, 1976.

[31] M. Peltoniemi, E. Vuori, Competitive Intelligence and Co-evolution within an Organisation Population, Proceedings of 6th European Conference on Knowledge Management, September 8-9, 2005, University of Limerick, Ireland, 2005.

[32] M.E. Porter, V.E. Millar, How Information Gives You Competitive Advantage, Harvard Business Review, Volume 63, No. 4, pp. 149-161, 1985.

[33] J. Prescott, The evolution of competitive intelligence: designing a process for action, Proposal Management, pp. 37-52, 1999

[34] D.S. Soper, A Framework for Automated Web Business Intelligence Systems, Proceedings of the 38th Annual Hawaii International Conference on System Sciences, USA, 2005.

[35] Z.H. Tang, J. MacLennan, Data Mining with SQL Server 2005, Indianapolis, IN, Wiley Publishing, 2005.

[36] T.S.H. Teo, W.Y. Choo, Assessing the Impact of Using the Internet for Competitive Intelligence, Information and Management, Volume 39, No. 1, pp. 67-83, 2001

[37] A.A. Thompson, A.J. Strickland, Strategic Management - Concepts and Cases - 13th ed. New York, NY, McGraw-Hill Higher Education, 2003.

[38] L. Vaughan, J. You, Mining Web hyperlink data for business information: The case of telecommunications equipment companies. Proceedings of the First IEEE International Conference on SignalImage Technology and Internet-Based Systems, Yaoundé, Cameroon, 2005.

[39] M. Vrincianu, L. Anica-Popa, I. Anica-Popa, Organizational memory: an approach from knowledge management and quality management of organizational learning perspectives, Amfiteatru Economic, No. 26, pp. 473-81, 2009.

[40] S. Wadhwa, J. Madaan, A Multi Criteria Decision Model for Alternative Selection in Reverse Logistics System, Studies in Informatics and Control, Vol. 16, No. 3, pp. 271-282, 2007.

[41] G. Windle, How Can Competitive Intelligence Practitioners Avoid Over-relying on the Internet, in Fleisher, C. S., Blenkhorn, D. L. (eds.), Controversies in Competitive Intelligence Westport, pp. 85-97, 2003.

[42] P. Zarate, Decision Making Process: A Collaborative Perspective, Studies in Informatics and Control, Vol. 17, No. 2, pp. 225-230, 2008.

[43] *** http://www.scip.org 